in vivo $33: 1403-1409$ (2019)

doi:10.21873/invivo.11617

Review

\title{
Optical Coherence Tomography of Choroid in Common Neurological Diseases
}

\author{
FEDERICO DI STASO ${ }^{1}$, MARCO CIANCAGLINI ${ }^{2}$, SOLMAZ ABDOLRAHIMZADEH ${ }^{1}$, \\ FABIAN D' APOLITO ${ }^{1}$ and GIANLUCA SCUDERI ${ }^{1}$ \\ ${ }^{1}$ Ophthalmology Unit, NESMOS Department, St. Andrea Hospital, Sapienza University of Rome, Rome, Italy; \\ ${ }^{2}$ Eye Clinic, San Salvatore Hospital, University of L'Aquila, L'Aquila, Italy
}

\begin{abstract}
The choroid is involved directly and indirectly in many pathological conditions such as age-related macular degeneration, myopia-related chorioretinal atrophy and central serous chorioretinopathy. Optical coherence tomography (OCT) has gradually become a fundamental part of modern resources in the hands of ophthalmologists. The enhanced depth imaging technique and swept-source OCT make a great contribution to conventional in vivo choroid assessment. This review focuses on the most common neurological conditions in which choroid assessment by OCT may provide help in early diagnosis and be used as an interdisciplinary followup tool. In order to avoid evaluation biases and misdiagnosis, the main and most common physiological and para-physiological conditions in which the choroid may show alterations are also reviewed.
\end{abstract}

Optical coherence tomography (OCT) has gradually become a fundamental part of modern resources in the hands of the ophthalmologists. As this technology improves, the nature of the choroid layer of the eye is becoming clearer and better characterized. The choroid vascular section consists of two parts: the outer layer of larger blood vessels called Haller's layer; and the inner layer of smaller arteries, arterioles and veins dedicated to the capillary network called Sattler's layer.

This article is freely accessible online.

Correspondence to: Marco Ciancaglini, Department of Life, Health and Environmental Science, University of L'aquila, L'Aquila, Italy. Tel: +39 3499778688, Fax: +39 0854216636, e-mail: marco.ciancaglini@cc.univaq.it

Key Words: Optical coherence tomography, choroid, Alzheimer, Parkinson, multiple sclerosis, phakomatoses, Sturge-Weber syndrome, review.
Considering unit per weight, the choroid has the highest blood flow ratio of all anatomical structures (1). The choroid is the only metabolic source for the avascular zone of the fovea (2). It also responsible for the vascular supply of the retinal pigment epithelium and outer retinal layers; furthermore, some portion of the optic nerve may also be supplied by the choroid (3).

The choroid is involved directly and indirectly in many pathological conditions such as age-related macular degeneration (4), myopia-related chorioretinal atrophy (5), central serous chorioretinopathy (6) and others, mostly because any choroid anomaly may lead dysregulation of blood flow and blood supply, with consequent photoreceptor death and vision loss (7).

The enhanced depth imaging technique (EDI) and swept source (SS) OCT have made a great contribution to conventional in vivo choroid assessment $(8,9)$, once achievable only through indocyanine green angiography and ultrasonography, both methods limited by low repeatability and low image resolution (10).

In 2016, Tan et al. showed in their review that any vascular disease can hypothetically affect the choroid (11) and tried to identify health conditions for which the choroid can be used as an indicator of systemic involvement.

This review focuses on the most common neurological conditions in which choroid assessment by OCT may provide help in early diagnosis or be used as an interdisciplinary follow-up tool.

In order to avoid evaluation biases and misdiagnosis, the following section reviews the main and most common physiological and para-physiological conditions in which the choroid may show alterations: Gender, age-related and circadian choroid variability.

\section{Gender Choroid Variability}

A large number of studies have reported statistically significant differences between males and females in 
choroidal thickness/volume. In 2011, Li et al. reported a higher choroidal thickness in males than in females (12), similar to the results of two other studies conducted in 2012 by Barteselli et al. (13) and Zeng et al. (14). A large study conducted by Wei et al. in 2013, involving more than 3,000 individuals, showed male gender to be associated with a thicker choroid, in particular, the mean subfoveal choroidal thickness was $254 \pm 107 \mu \mathrm{m}$. It is also worth mentioning that the mean age of the study subjects was 65 years (15). In contrast, in 2014, Sanchez-Cano et al. showed no statistically significant difference between genders (16); in the same year, Ruiz Medrano et al. Similarly found no difference. It is important to note that this study was conducted using SSOCT (17). In 2015, other studies $(18,19)$ once again showed that the choroid is thicker in males than females using/comparing SD-OCT data.

In conclusion, the difference in choroidal thickness between males and females should be considered when studying the choroid layer, taking into account that different techniques may lead to different results.

\section{Age-related Choroid Variability}

One of the main factors influencing the choroidal thickness seems to be age. In 2009, Margolis et al. studied the choroidal thickness of more than 50 healthy eyes at various points using the EDI OCT technique. The results showed a $15.6 \mu \mathrm{m}$ subfoveal decrease in choroidal thickness for each decade of life (20). In 2010, Ikuno et al. showed a significant negative association between choroidal thickness and age in healthy Japanese (21). In the same year, Manjunath et al. found a trend for an age-related decrease in choroidal thickness in testing 34 participants (22). In 2012, Barteselli et al. demonstrated a negative correlation between age and axial length (13). Furthermore, in 2014, Rhodes et al. showed a lower age-related choroid peripapillary thickness in a group of African descent and one of European descent (23). In 2015, Gupta and colleagues analyzed more than 500 participants ranging in age from 45 to 85 years using new automated choroidal segmentation software in order to provide the best reliability. In a multiple linear regression model, younger age was significantly associated with a thicker subfoveal choroid (24).

\section{Circadian Choroid Variability}

Choroidal thickness seems to be subject to diurnal variations. In 2011, Chakraborty et al. observed significant variation in choroidal thickness during the day, with no difference between myopic and emmetropic patients; the choroid was found to be thinner in the morning (25). In 2012, Tan et al. found a significant diurnal choroidal thickness variation with mean diurnal difference of $33.7 \mu \mathrm{m}$ associated with a progressive decrease from 9 a.m. to 5 p.m. (26).
Another similar study conducted by Usui et al. showed a similar pattern of variation in thickness in 38 eyes of 19 healthy volunteers (27). In contrast, during the same year, Toyokawa et al. found that the diurnal variation of choroidal thickness may be insignificant in some individuals and variable in others, however, with good correlation between their two eyes (28). In 2013, Osmanbasoglu et al. again reported no significant variation choroidal thickness from 9 a.m. to 4 p.m. (29). Since there is no consensus on the choroid diurnal variation, assessing choroidal thickness at different times in the same individual may help to find a hypothetic pattern in individual variation.

\section{Materials and Methods}

Literature search. MEDLINE/PubMed was the primary database source used for this research. Terms pertinent to OCT of the choroid in neurological diseases were used (e.g. OCT choroid, choroid, Alzheimer, dementia, Parkinson, multiple sclerosis, phacomatosis, neurological disease) as well as abbreviations, synonyms and alternative spellings (e.g. phacomatosis). The final search was performed on 16th March 2019.

\section{Results}

Alzheimer's disease. Alzheimer's disease (AD) is a common pathology and the most common form of dementia (30). In the last years, many causes and mechanisms have been elucidated in the pathogenesis of this disease, such as microvascular factors (31).

Given that many embryological, physiological and even anatomical properties are shared between cerebral small vessel circulation and retinal circulation (32), many authors have conducted extensive studies in order to find correlation between choroidal thickness and AD. Bayhan et al. in 2014 used an RTVue OCT system to obtain, among other parameters, the choroidal thickness with a cross line retinal scan pattern, analyzing the chorioretinal interface adjacent to the zero delay zone of 31 consecutive patients with AD and 30 controls (33). The mean measurements of choroidal thickness at each location were significantly lower in patients with $\mathrm{AD}$ than controls, except measurements $3.0 \mathrm{~mm}$ temporal to the fovea $(p=0.067)$.

The study conducted by Gharbiya et al. (34) on 42 eyes of 21 patients (mean age $=73.1 \pm 6.9$ years) with a diagnosis of mild to moderate AD and 42 eyes of 21 age-matched controls (34) was performed using spectral domain (SD)OCT images obtained by EDI modality. All measurements were made of the subfoveal choroid, at 500 and 1,500 $\mu \mathrm{m}$ starting from the center of the fovea. The choroidal thickness was significantly thinner at each zone in those with AD than in control eyes $(p<0.05)$.

In 2016, Bulut et al. used EDI-OCT to study the choroidal thickness in patients with $\mathrm{AD}$ and in patients with mild cognitive impairment (Figure 1) (35). Mild cognitive 

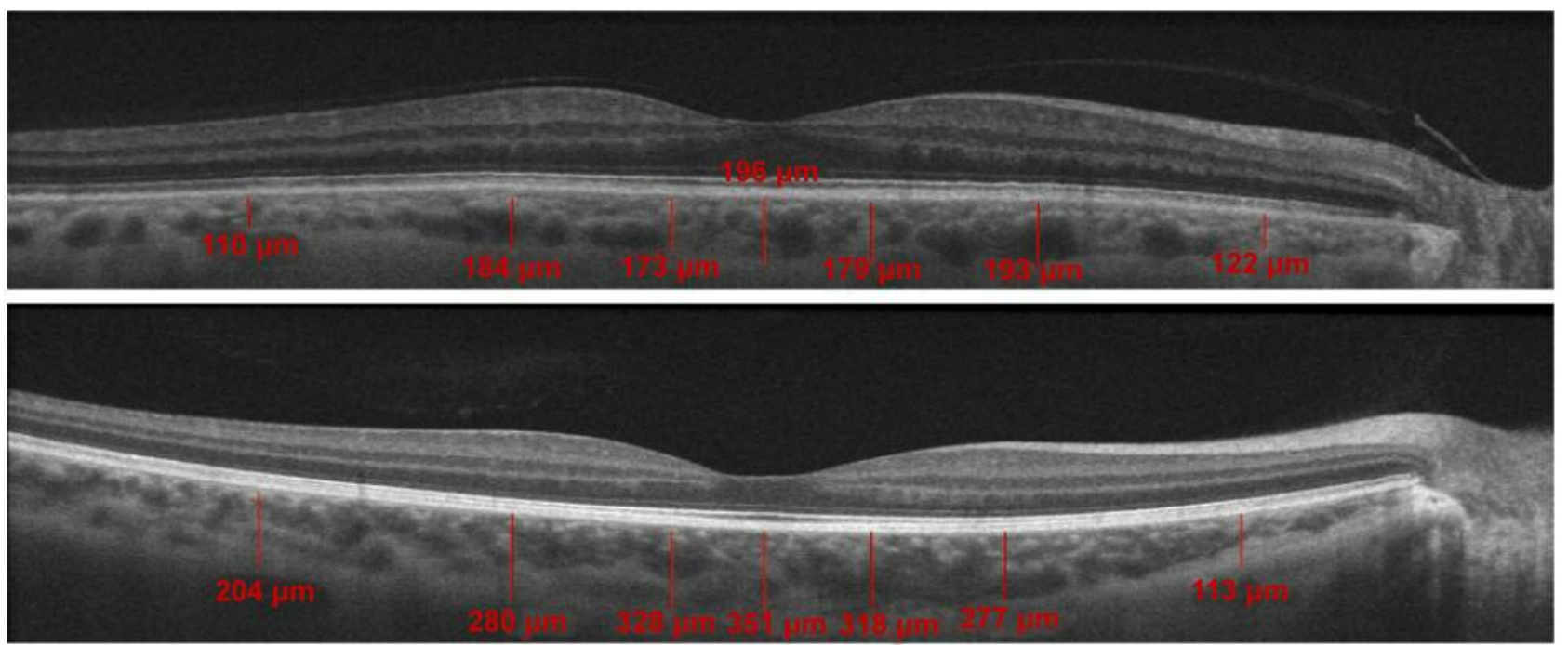

Figure 1. Measurement of choroidal thickness in healthy (top) and patients with Alzheimer's disease (bottom) revealed a statistically significant difference at each location (35).

impairment is considered a transitional phase towards dementia, with a similar pathogenesis to that of $\mathrm{AD}(36)$. The measurements were obtained from the outer edge of the hyper-reflective retinal pigment epithelium to the inner sclera at seven locations: at the fovea; at 500, 1,500, and 3,000 $\mu \mathrm{m}$ temporal to the fovea; and at 500,1,500, and 3,000 $\mu \mathrm{m}$ nasal of the fovea. Each measurement was repeated three times in order to calculate the average value. There was statistically significant choroidal thinning in AD and patients with mild cognitive impairment compared to the controls.

Another important aspect is atrophy of choroidal capillaries due to normal aging (37). This may lead to doubts about choroidal thinning in patients with $\mathrm{AD}$ patients since in the majority of cases, the patients under consideration are elderly. Cunha et al. in 2017 (38) used the SD-OCT in EDI mode to examine 50 patients with a diagnosis of mild AD (mean age $=73.1$ years), 152 patients without $\mathrm{AD}$ (mean age $=71.03$ years), and 50 elderly without $\mathrm{AD}$ (mean age $=82.14$ years). In the patients with $\mathrm{AD}$, the choroidal thickness was lower in all the examined locations $(p<0.001)$ compared with the agematched, and elderly groups. Choroidal thinning was even more pronounced temporally to the fovea. Choroidal thinning was found to be more pronounced in elderly compared to younger patients (38); nonetheless, in patients with $\mathrm{AD}$, the choroid was significantly thinner even when compared with an elderly control group.

\section{Parkinson's Disease}

The second most common neurodegenerative disease affecting the central nervous system is Parkinson's disease
(PD). Although the causes remain unknown, there is progressive degeneration of extrapyramidal dopaminergic neurons. Common findings are Lewy bodies accumulated in the central, peripheral and autonomic nervous system (39). Eraslan et al. hypothesized in 2016 that a choroidal involvement in PD may be due to blood flow irregularities or phenomena of atrophy. They examined the lamina cribrosa and choroidal thicknesses in 44 eyes of 22 patients with PD and 50 eyes of 25 healthy individuals using EDIOCT (40). The choroidal thickness of the PD group was significantly less compared to the controls, in the subfoveal region, and $1.5 \mathrm{~mm}$ temporal and $1.5 \mathrm{~mm}$ nasal to the fovea. In 2017, Moschos and Chatziralli used EDI-OCT to analyze the retinal and choroidal thickness of 31 patients with PD compared to 25 healthy controls. The results were similar to those of Eraslan et al., showing a statistically significant thinning in all the examined zones: nasal, temporal, inferior and superior at $1.5 \mathrm{~mm}$ and $3 \mathrm{~mm}$ from the fovea. According to the authors, the large difference in choroidal thickness between the PD and control groups gives more credit to the involvement of vascular changes besides the neurodegenerative process, both potentially responsible for clinical risk and disease progression (41).

In 2018, Satue et al. used different resources to investigate choroidal thickness in patients with PD SS-OCT (42). Fifty eyes of 50 patients were examined and compared to 54 eyes of 54 healthy controls following the macular) and peripapillary area. They showed that the EDI SD-OCT technique has a limited reliability, mostly because the inner and outer border of the choroid are determined manually by the observer; furthermore, SS-OCT, can easily overcome the 
choroid light scattering (43) of SD-OCT. The final results showed a thickened macular and peripapillary choroid, in contrast to the previous studies. Although vascular changes may be involved (44), the authors themselves suggest alterations in perivascular connective tissue density as a cause and not hypoperfusion alone.

\section{Multiple Sclerosis}

Multiple sclerosis (MS) is a disease with inflammatory and chronic axonal demyelination and subsequent degeneration, which may involve the optic nerve (45-47). Esen et al. in 2015 , conducted a study on choroidal vascular changes in MS-affected patients using EDI-OCT (48). The study was conducted taking into account and comparing a positive or negative history/clinical report of optic neuritis episodes. Each measurement was taken at the fovea and at 500- $\mu \mathrm{m}$ intervals temporal and nasal to the fovea up to a total of six intervals per patient. The choroidal thickness at all measured locations was significantly less in patients with MS compared to healthy controls regardless of history of optic neuritis. The authors suggested that choroidal thinning may be the result of a perfusion impairment due to a systemic inflammatory response (49). It has been hypothesized that endothelin-1 (ET1), found to be increased in patients with MS (50), may play a role in this scenario, given its vasoconstrictive effect.

\section{Phakomatoses}

Phakomatoses are a group of hereditary multisystem disorders characterized by a pattern of inheritance, variable severity and higher risk of malignant transformation (51) and include neurofibromatosis, tuberous sclerosis and von Hippel Lindau disease (52). These three neurocutaneous diseases share the same aforementioned characteristics and can be defined as true phacomatoses (53).

Neurofibromatosis type I (NF1) is an autosomal dominant disease due to 17 p11.2 gene deletion or suppression (54), with several ophthalmic features included in the diagnostic criteria such as Lisch nodules and optic glioma (55). It is often difficult to find choroidal alteration via fundus examination in NF1, on the other hand, the use of the OCT may show choroidal nodules whose number is correlated with the number of Lisch nodules on the iris (56). In 2012, Viola et al. found choroidal nodules in $82 \%$ of 190 examined eyes using near-infrared reflectance (NIR) and proposed choroidal nodules be included in the diagnostic criteria for NF1 (57). Many other choroidal features have been found using OCT, such as thickness changes in the retina overlying the nodules (58) and loss of lucency in the choroid over nodules (59). From the point of view of choroidal thickness, Abdolrahimzadeh et al. showed generalized choroidal and retinal thinning in patients with NF1 (60). Furthermore, in the same study, NIR-detected nodules were shown to be related to two different types of hyper-reflective choroidal nodules detected by EDI-OCT: round-shaped and welldefined NIR nodules with dome-shaped hyper-reflective alteration on EDI-OCT, and poorly defined NIR nodules with flat, irregular nodules on EDI-OCT.

Tuberus sclerosis complex is a genetic disorder due to TSC complex subunit 1 (TSC1) and TSC2 gene mutations characterized by shagreen patches, facial angiofibroma, ungula fibroma, skin lesions, cortical tubers and retinal lesions (61). Sometimes additional features may be present such as epilepsy, mental retardation, autism and other behavioral disorders (62). The retinal lesions are defined as retinal astrocytic hamartomas, identifiable in approximately 50\% of patients (63-65). In 2016, Pichi et al. classified these hamartomas into four groups using SD-OCT (66), taking into consideration morphology, retinal layer involvement, tumor margins and other parameters. To the best of our knowledge, there are no specific choroidaI alteration in tuberus sclerosis complex.

von Hippel Lindau disease is an autosomal dominant genetic disease due to 3p25-26 tumor-suppressor gene variation (52). The most common presentation of this condition is the presence of vascular tumors of the central nervous system (hemangioblastoma) and retinal capillary hemangioblastoma (53). The most common and early presentation is retinal hemangioblastoma, which may occur in up to $85 \%$ of cases (67) and it is made up of capillary spaces with pericytes and stromal cells. Shields et al. showed and described the main OCT characteristics of retinal hemangioblastoma (68) but there are not enough data in literature about choroidal involvement.

\section{Sturge-Weber Syndrome}

Sturge-Weber syndrome is a neuro-oculo-dermal disease that affects the normal development of certain blood vessels in the brain, skin and eyes from birth (69). Choroidal hemangioma is a frequent condition in this syndrome; it may cause choroidal thickening and a diffuse red appearance on fundus examination (70). In 2016, Abdolrahimzadeh et al. studied 12 patients with Sturge-Weber syndrome and found that the overall mean choroidal thickness in affected and fellow eyes was significantly higher than in control eyes $(266.5 \mu \mathrm{m})(71)$. To the best of our knowledge, there are no other reports in literature about the choroidal thickness comparing between patients with Sturge-Weber syndrome and healthy controls.

\section{Conclusion}

Difference in choroidal thickness between males and females should be considered when studying the choroidal layer, even age seems to play a role in subfoveal choroidal thickness because a younger age is associated with a thicker 
subfoveal choroid. In AD, many authors have conducted extensive studies in order to find a correlation between choroidal thickness and this pathology. In AD, the choroid was thinner even when compared with a control group of advanced age. In patients with Parkinson's disease, the choroid was thinner as long as the EDI-OCT method was used. Using SS-OCT the results showed a thickened choroid in patients with Parkinson's, showing that different techniques may lead to different results.

In MS, the choroid seems to be thinner but literature is scarce. Patients with phakomatoses may show several alterations on OCT but from the point of view of choroidal thickness, the choroid was thicker in neurofibromatosis type 1. Even in this case, the literature is scarce. For tuberous sclerosis complex and von Hippel Lindau syndrome, there are not enough data in literature to establish a general consensus about choroid thickness.

In Sturge-Weber syndrome the literature is limited, however, choroid thickness seems to be significantly higher compared to controIs.

OCT technology has become a fundamental instrument in the hands of the ophthalmologist, this is why the choroid layer is becoming increasingly more characterized. Despite constant progress in OCT technology and diagnostic capabilities, certain fields remain unclear. In neurological diseases, OCT may play an important role as a diagnostic and follow-up tool. In common neurological pathologies, such as AD and Parkinson's disease, the literature offers limited, but good resources for better understanding choroidal characteristics on OCT. In rare pathologies, such as phakomatosis, the literature is too limited and further studies are needed.

\section{References}

1 Alm A and Bill A: Ocular and optic nerve blood flow at normal and increased intraocular pressures in monkeys (Macaca irus): A study with radioactively labelled microspheres including flow determinations in brain and some other tissues. Exp Eye Res 15 15-29, 1973. PMID: 4630581.

2 Mrejen S and Spaide RF: Optical coherence tomography: imaging of the choroid and beyond. Surv Ophthalmol 58: 387429, 2013. PMID: 23916620. DOI: 10.1016/j.survophthal. 2012.12.001

3 Hayreh SS: The blood supply of the optic nerve head and the evaluation of it - myth and reality. Prog Retin Eye Res 20: 563593, 2001. PMID: 11470451.

4 Ma L, Tang SM, Rong SS, Chen H, Young AL, Kumaramanickavel $\mathrm{G}$, Pang CP and Chen L: Association of PEDF polymorphisms with age-related macular degeneration and polypoidal choroidal vasculopathy: a systematic review and metaanalysis. Sci Rep 5: 9497, 2015. PMID: 25820866. DOI: 10.1038/srep09497.

5 Chang L, Pan CW, Ohno-Matsui K, Cheung GC, Gazzard G, Koh V, Hamzah H, Tai ES, Lim SC, Mitchell P, Young TL, Aung T, Wong TY and Saw SM: Myopia-related fundus changes in
Singapore adults with high myopia. Am J Ophthalmol 155: 991999 e991, 2013. PMID: 23499368. DOI: 10.1016/j.ajo.2013.01.016

6 Daruich A, Matet A, Dirani A, Bousquet E, Zhao M3, Farman N, Jaisser $\mathrm{F}$ and Behar-Cohen F: Central serous chorioretinopathy: Recent findings and new physiopathology hypothesis. Prog Retin Eye Res 48: 82-118, 2015. PMID: 26026923. DOI: 10.1016/ j.preteyeres.2015.05.003

7 Cao J, McLeod S, Merges CA and Lutty GA: Choriocapillaris degeneration and related pathologic changes in human diabetic eyes. Arch Ophthalmol 116: 589-597, 1998. PMID: 9596494.

8 Spaide RF, Koizumi H and Pozzoni MC: Enhanced depth imaging spectral-domain optical coherence tomography. Am J Ophthalmol 146: 496-500, 2008. PMID: 18639219. DOI: 10.1016/j.ajo.2008.05.032

9 Rahman W, Chen FK, Yeoh J, Patel P, Tufail A and Da Cruz L: Repeatability of manual subfoveal choroidal thickness measurements in healthy subjects using the technique of enhanced depth imaging optical coherence tomography. Invest Ophthalmol Vis Sci 52: 2267-2271, 2011. PMID: 21087970. DOI: 10.1167 /iovs.10-6024

10 Guyer DR, Puliafito CA, Mones JM, Friedman E, Chang W and Verdooner SR: Digital indocyanine-green angiography in chorioretinal disorders. Ophthalmology 99: 287-291, 1992. PMID: 155322 .

11 Tan KA, Gupta P, Agarwal A, Chhablani J, Cheng CY, Keane PA and Agrawal R: State of science: Choroidal thickness and systemic health. Surv Ophthalmol 61(5): 566-581, 2016. DOI: 10.1016/j.survophthal.2016.02.007

$12 \mathrm{Li} \mathrm{XQ}$, Larsen M and Munch IC: Subfoveal choroidal thickness in relation to sex and axial length in 93 Danish university students. Invest Ophthalmol Vis Sci 52: 8438-8441, 2011. PMID: 21917938. DOI: 10.1167/iovs.11-8108

13 Barteselli G, Chhablani J, El-Emam S, Wang H, Chuang J, Kozak I, Cheng L, Bartsch DU and Freeman WR: Choroidal volume variations with age, axial length, and sex in healthy subjects: A three-dimensional analysis. Ophthalmology 119: 2572-2578, 2012. PMID: 22921388. DOI: 10.1016/j.ophtha. 2012.06.065

14 Zeng J, Liu R, Zhang XY, Li JQ, Chen X, Pan JY, Tang SB and Ding XY: Relationship between gender and posterior pole choroidal thickness in normal eyes. Zhonghua Yan Ke Za Zhi 48: 1093-1096, 2012. PMID: 23336414.

15 Wei WB, Xu L, Jonas JB, Du KF, Wang S, Chen CX, Xu J, Wang YX, Zhou JQ and You QS: Subfoveal choroidal thickness: The Beijing Eye Study. Ophthalmology 120: 175-180, 2013. PMID: 23009895. DOI: 10.1016/j.ophtha.2012.07.048

16 Sanchez-Cano A, Orduna E, Segura F, Lopez C, Cuenca N, Abecia E and Pinilla I: Choroidal thickness and volume in healthy young White adults and the relationships between them and axial length, ammetropy and sex. Am J Ophthalmol 158: 574-583 e571, 2014. PMID: 24907431. DOI: 10.1016/j.ajo.2014. 05.035

17 Ruiz-Medrano J, Flores-Moreno I, Pena-Garcia P, Montero JA, Duker JS and Ruiz-Moreno JM: Macular choroidal thickness profile in a healthy population measured by swept-source optical coherence tomography. Invest Ophthalmol Vis Sci 55: 35323542, 2014. PMID: 24845638. DOI: 10.1167/iovs.14-13868

18 Ooto S, Hangai M and Yoshimura N: Effects of sex and age on the normal retinal and choroidal structures on optical coherence tomography. Curr Eye Res 40: 213-225, 2015. PMID: 25153829. DOI: $10.3109 / 02713683.2014 .952828$ 
19 Tuncer I, Karahan E, Zengin MO, Atalay E and Polat N: Choroidal thickness in relation to sex, age, refractive error, and axial length in healthy Turkish subjects. Int Ophthalmol 35: 403410, 2015. PMID: 24950905. DOI: 10.1007/s 10792-014-9962-4

20 Margolis R and Spaide RF: A pilot study of enhanced depth imaging optical coherence tomography of the choroid in normal eyes. Am J Ophthalmol 147: 811-815, 2009. PMID: 19232559. DOI: $10.1016 /$ j.ajo.2008.12.008

21 Ikuno Y, Kawaguchi K, Nouchi T and Yasuno Y: Choroidal thickness in healthy Japanese subjects. Invest Ophthalmol Vis Sci 51: 2173-2176, 2010. PMID: 19892874. DOI: 10.1167/ iovs.09-4383

22 Manjunath V, Taha M, Fujimoto JG and Duker JS: Choroidal thickness in normal eyes measured using Cirrus HD optical coherence tomography. Am J Ophthalmol 150: 325-329 e321, 2010. PMID: 20591395. DOI: 10.1016/j.ajo.2010.04.018

23 Rhodes LA, Huisingh C, Johnstone J, Fazio MA, Smith B, Wang L, Clark M, Downs JC, Owsley C, Girard MJ, Mari JM and Girkin CA: Peripapillary choroidal thickness variation with age and race in normal eyes. Invest Ophthalmol Vis Sci 56: 18721879, 2014. PMID: 25711640. DOI: 10.1167/iovs.14-16179

24 Gupta P, Jing T, Marziliano P, Cheung CY, Baskaran M, Lamoureux EL, Wong TY, Cheung CM and Cheng CY: Distribution and determinants of choroidal thickness and volume using automated segmentation software in a population-based study. Am J Ophthalmol 159: 293-301 e293, 2015. PMID: 25447120. DOI: $10.1016 /$ j.ajo.2014.10.034

25 Chakraborty R, Read SA and Collins MJ: Diurnal variations in axial length, choroidal thickness, intraocular pressure, and ocular biometrics. Invest Ophthalmol Vis Sci 52: 5121-5129, 2011. PMID: 21571673. DOI: 10.1167/iovs.11-7364

26 Tan CS, Ngo WK, Chew MC, Li KZ, Lim LW and Sadda SR: Diurnal variation of retinal thickness measured by optical coherence tomography in normal adults. Invest Ophthalmol Vis Sci 53: 1639, 2012. PMID: 22441497. DOI: 10.1167/iovs.129566

27 Usui S, Ikuno Y, Akiba M, Maruko I, Sekiryu T, Nishida K and Iida T: Circadian changes in subfoveal choroidal thickness and the relationship with circulatory factors in healthy subjects. Invest Ophthalmol Vis Sci 53: 2300-2307, 2012. PMID: 22427554. DOI: $10.1167 /$ iovs.11-8383

28 Toyokawa N, Kimura H, Fukomoto A and Kuroda S: Difference in morning and evening choroidal thickness in Japanese subjects with no chorioretinal disease. Ophthalmic Surg Lasers Imaging 43: 109-114, 2012. PMID: 22320414. DOI: 10.3928/1542887720120102-06

29 Osmanbasoglu OA, Alkin Z, Ozkaya A, Ozpınar Y, Yazici AT and Demirok A: Diurnal choroidal thickness changes in normal eyes of Turkish people measured by spectral domain optical coherence tomography. J Ophthalmol 2013: 1-6, 2013. PMID: 23589769. DOI: $10.1155 / 2013 / 687165$

30 Alzheimer's Association: 2012 Alzheimer's disease facts and figures. Alzheimers Dement 8: 131-168, 2012. PMID: 22404854.

31 Kalaria RN, Akinyemi R and Ihara M: Does vascular pathology contribute to Alzheimer changes? J Neurol Sci 322: 141-147, 2012. DOI: $10.1016 /$ j.jns.2012.07.032

32 Patton N, Aslam T, Macgillivray J, Pattie A, Deary I and Dhillon B: Retinal vascular image analysis as a potential screening tool for cerebrovascular disease. J Anat 206: 318-348, 2005. PMID: 15817102
33 Bayhan HA, Aslan Bayhan S, Celikbilek A, Tanık N and Gürdal $\mathrm{C}$ : Evaluation of the chorioretinal thickness changes in Alzheimer's disease using spectral-domain optical coherence tomography. Clin Exp Ophthalmol 43: 145-151, 2014. PMID: 24995484. DOI: $10.1111 /$ ceo.12386

34 Gharbiya M, Trebbastoni A, Parisi F, Manganiello S, Cruciani F, D'Antonio F, De Vico U, Imbriano L, Campanelli A and De Lena C: Choroidal thinning as a new finding in Alzheimer's disease: Evidence from enhanced depth imaging spectral domain optical coherence tomography. J Alzheimers Dis 40: 907-917, 2014. PMID: 24577467. DOI: 10.3233/JAD-132039

35 Bulut M, Yaman A, Erol MK, Kurtuluş F, Toslak D, Doğan B, Turgut Çoban D and Kaya Başar E: Choroidal thickness in patients with mild cognitive impairment and Alzheimer's type dementia. J Ophthalmol 2016: 1-7, 2016. PMID: 26925259. DOI: $10.1155 / 2016 / 7291257$

36 Petersen RC, Doody R, Kurz A, Mohs RC, Morris JC, Rabins PV, Ritchie K, Rossor M, Thal L and Winblad B: Current concepts in mild cognitive impairment. Arch Neurol 58: 19851992, 2001. PMID: 11735772.

37 Podoleanu AG and Rosen RB: Combinations of techniques in imaging the retina with high resolution. Prog Retin Eye Res 27: 464-499, 2008. PMID: 18495519. DOI: 10.1016/j.preteyeres. 2008.03.002

38 Cunha JP, Proença R, Dias-Santos A, Melancia D, Almeida R, Águas $\mathrm{H}$, Santos BO, Alves M, Ferreira J, Papoila AL, Louro C and Castanheira-Dinis A: Choroidal thinning: Alzheimer's disease and aging. Alzheimer Dement (AMST) 8: 11-17, 2017. PMID: 28435851. DOI: 10.1016/j.dadm.2017.03.004

39 Capriotti T and Terzakis K: Parkinson disease. Home Healthc Now 34: 300-307, 2016. PMID: 27243427. DOI: 10.1097/NHH. 0000000000000398

40 Eraslan M, Cerman E, Yildiz Balci S, Celiker H, Sahin O, Temel A, Suer D and Tuncer Elmaci N: The choroid and lamina cribrosa is affected in patients with Parkinson's disease: enhanced depth imaging optical coherence tomography study. Acta Ophthalmol 94: 68-75, 2016. PMID: 26268377. DOI: 10.1111/aos.12809

41 Moschos MM and Chatziralli IP: Evaluation of choroidal and retinal thickness changes in Parkinson's disease using spectral domain optical coherence tomography. Semin Ophthalmol 33: 494-497, 2018. PMID: 28394663. DOI: 10.1080/08820538. 2017.1307423

42 Satue M, Obis J, Alarcia R, Orduna E, Rodrigo MJ, Vilades E, Gracia H, Otin S, Fuertes MI, Polo V, Larrosa JM, Pablo LE and Garcia-Martin E: Retinal and choroidal changes in patients with Parkinson's disease detected by swept-source optical coherence tomography, Curr Eye Res 43: 109-111, 2018. PMID: 29111842. DOI: $10.1080 / 02713683.2017 .1370116$

43 Hirata M, Tsujikawa A, Matsumoto A, Hangai M, Ooto S, Yamashiro K, Akiba M and Yoshimura N: Macular choroidal thickness and volume in normal subjects measured by sweptsource optical coherence tomography. Invest Ophthalmol Vis Sci 52: 4971-4978, 2011. DOI:10.1167/iovs.11-7729

44 Vale TC, Caramelli P and Cardoso F: Clinicoradiological comparison between vascular Parkinsonism and Parkinson's disease. J Neurol Neurosurg Psychiatry 86: 547-553, 2015. DOI: $10.1136 /$ jnnp-2014-307867

45 Compston A and Coles A: Multiple sclerosis. Lancet 372: 15021517, 2008. PMID: 18970977. DOI: 10.1016/S0140-6736(08) 61620-7 
46 Akarsu C, Tan FU and Kendi T: Color Doppler imaging in optic neuritis with multiple sclerosis. Graefes Arch Clin Exp Ophthalmol 242: 990-994, 2004. PMID: 15592867. DOI: 10.1007/s00417-004-0948-1

47 Murphy OC, Kwakyi O, Iftikhar M, Zafar S, Lambe J, Pellegrini N, Sotirchos ES, Gonzalez-Caldito N, Ogbuokiri E, Filippatou A, Risher H, Cowley N, Feldman S, Fioravante N, Frohman EM, Frohman TC, Balcer LJ, Prince JL, Channa R, Calabresi PA and Saidha S: Alterations in the retinal vasculature occur in multiple sclerosis and exhibit novel correlations with disability and visual function measures. Mult Scler 16: 1352458519845116, 2019. DOI: $10.1177 / 1352458519845116$

48 Esen E, Sizmaz S, Demir T, Demirkiran M, Unal I and Demircan $\mathrm{N}$ : Evaluation of choroidal vascular changes in patients with multiple sclerosis using enhanced depth imaging optical coherence tomography. Ophthalmologica 235: 65-71, 2016. PMID: 26485541. DOI: 10.1159/000441152

49 Grieshaber MC, Mozaffarieh M and Flammer J: What is the link between vascular dysregulation and glaucoma? Surv Ophthalmol 52(suppl 2): S144-S154, 2007. PMID: 17998040. DOI: 10.1016/j.survophthal.2007.08.010

50 Pache M, Kaiser HJ, Akhalbedashvili N, Lienert C, Dubler B, Kappos L and Flammer J: Extraocular blood flow and endothelin1 plasma levels in patients with multiple sclerosis. Eur Neurol 49: 164-168, 2003. PMID: 12646761. DOI: 10.1159/000069085

51 Cichowski K and Jacks T: NF1 tumor-suppressor gene function: Narrowing the GAP. Cell 104: 593-604, 2001. PMID: 11239415.

52 Lonser RR, Glenn GM, Walther M, Chew EY, Libutti SK, Linehan WM and Oldfield EH: von Hippel-Lindau disease. Lancet 361: 2059-2067, 2003. PMID: 12814730. DOI: 10.1016/ S0140-6736(03)13643-4

53 Abdolrahimzadeh S, Plateroti AM, Recupero SM and Lambiase A: An update on the ophthalmologic features in phakomatoses. J Ophthalmol 2016: 1-15, 2016. PMID: 27493794. DOI: $10.1155 / 2016 / 3043026$

54 Jett $\mathrm{K}$ and Friedman J: Clinical and genetic aspects of neurofibromatosis 1. Genet Med 12: 1-11, 2010. PMID: 20027112.

55 Recupero SM, Abdolrahimzadeh S, De Dominicis M and Mollo R: Sturge-Weber syndrome associated with naevus of Ota. Eye 12: 212-213, 1998. PMID: 9683940.

56 Makino S, Tampo H, Y Arai Y and Obata H: Correlation between choroidal abnormalities, Lisch nodules, and age inpatients with neurofibromatosis type 1. Clin Ophthalmol 8: 165-168, 2014. PMID: 24403820. DOI: 10.2147/OPTH.S56327

57 Viola F, Villani E, Natacci F, Selicorni A, Melloni G, Vezzola D, Barteselli G, Mapelli C, Pirondini C and Ratiglia R: Choroidal abnormalities detected by near-infrared reflectance imaging as a new diagnostic criterion for neurofibromatosis 1. Ophthalmology 119: 369-375, 2012. PMID: 21963267. DOI: 10.1016/ j.ophtha. 2011.07.046

58 Ayata A, Unal M, Ersanli D and Tatlipinar S: Near infrared fluorescence and OCT features of choroidal abnormalities in type 1 neurofibromatosis. Clin Exp Ophthalmol 36: 390-392, 2008. PMID: 18700931. DOI: 10.1111/j.1442-9071.2008. 001742.x

59 Rao RC and Choudhry N: Enhanced depth imaging spectral domain optical coherence tomography findings in choroidal neurofibromatosis. Ophthalmic Surg Lasers Imaging Retina 45: 466-468, 2014. PMID: 25153660. DOI: 10.3928/2325816020140818-01
60 Abdolrahimzadeh S, Felli L, Plateroti R, Plateroti AM, Giustini S, Calvieri S and Recupero SM: Morphologic and vasculature features of the choroid and associated choroid retinal thickness alterations in neurofibromatosis type 1. Br J Ophthalmol 99: 789-793, 2015. PMID: 25488947. DOI: 10.1136/bjophthalmol2014-306062

61 Curatolo P, Bombardieri R and Jozwiak S: Tuberous sclerosis. Lancet 372: 657-668, 2008. PMID: 18722871. DOI: 10.1016/ S0140-6736(08)61279-9

62 Curatolo P, Moavero R and de Vries PJ: Neurological and neuropsychiatric aspects of tuberous sclerosis complex. Lancet Neurol 14: 733-745, 2015. PMID: 26067126.

63 Nyboer JH, Robertson DM and Gomez MR: Retinal lesions in tuberous sclerosis. Arch Ophthalmol 94: 1277-1280, 1976. PMID: 949267.

64 Robertson DM: Ophthalmic manifestations of tuberous sclerosis. Ann NY Acad Sci 615: 17-25, 1991. PMID: 2039142.

65 Samueli S, Abraham K, Dressler A, Groeppel G, Jonak C, Muehlebner A, Prayer D, Reitner A, Feucht M and Pädiatrisches TSC-Zentrum Wien: Tuberous sclerosis complex: New criteria for diagnostic work-up and management. Wien Klin Wochenschr 127: 619-630, 2015. PMID: 25860851. DOI: 10.1007/s00508015-0758-y

66 Pichi F, Massaro D, Serafino M, Carrai P, Giuliari GP, Shields CL, Veronese C, Ciardella AP and Nucci P: Retinal astrocytic hamartoma: Optical coherence tomography classification and correlation with tuberous sclerosis complex. Retina 36: 11991208, 2016. PMID: 26618803. DOI: 10.1097/IAE.00 000000 00000829

67 Wong WT and Chew EY: Ocular von Hippel-Lindau disease: Clinical update and emerging treatments. Curr Opin Ophthalmol 19: 213-217, 2008. PMID: 18408496. DOI: 10.1097/ICU.0b013 e $3282 \mathrm{fb} 7 \mathrm{c} 04$

68 Shields CL, Materin MA and Shields JA: Review of optical coherence tomography for intraocular tumors. Curr Opin Ophthalmol 16: 141-154, 2005. PMID: 15870570.

69 Higueros E, Roe E, Granell E and Baselga E: Sturge-Weber syndrome: A review. Actas Dermosifiliogr 108: 407-417, 2017. PMID: 28126187. DOI: 10.1016/j.ad.2016.09.022

70 Arora KS, Quigley HA, Comi AM, Miller RB and Jampel HD: Increased choroidal thickness in patients with Sturge-Weber syndrome. JAMA Ophthalmol 131: 1216-1219, 2013. PMID: 23828561. DOI: 10.1001/jamaophthalmol.2013.4044

71 Abdolrahimzadeh S, Scavella V, Battaglia D and Recupero SM: Spectral domain optical coherence tomography of choroidal and outer retinal layer thickness in the Sturge Weber syndrome. Curr Eye Res 41: 1614-1617, 2016. PMID: 27159379. DOI: 10.3109/ 02713683.2015 .1135962
Received May 14, 2019

Revised July 7, 2019

Accepted July 12, 2019 